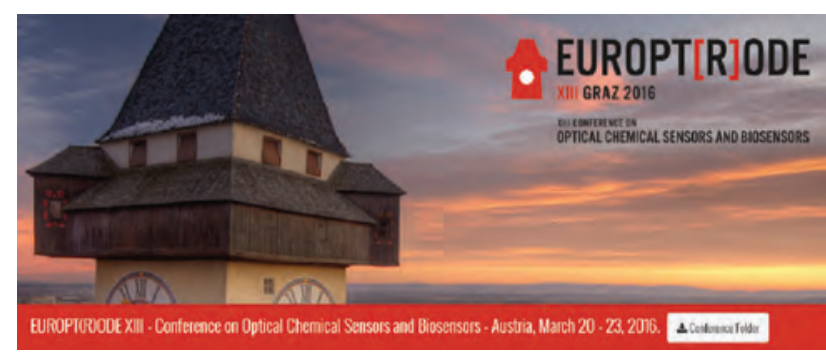

EUROPT(R)ODE XIII - Conference on Optical Chemical Sensors and Biosensors

A conferência bienal EUROPT(R)ODE é uma das principais conferências em sensores ópticos. Desde 1992 que a conferência EUROPT(R)ODE tem sido um fórum para cientistas e engenheiros provenientes de universidades, institutos de investigação e da indústria de todo o mundo. A conferência atrai cerca de 300 participantes e concentra-se em todos os aspectos relacionados com a investigação, desenvolvimento e aplicações de sensores químicos ópticos e biossensores.

Os temas da conferência incluem: Novos receptores moleculares e indicadores; Nanomateriais para detecção óptica; Sensores e materiais sensores sustentáveis; Materiais para biossensores; Novos princípios de detecção (plasmónica; óptica não-linear; espectroscopia molecular; luminescência); Aplicações de sensores ópticos em: monitorização ambiental; Controlo de processos e segurança; Análise de alimentos; Diagnósticos médicos; Lab-on-a-chip.

info@europtrode2016.eu

http://www.europtrode2016.eu

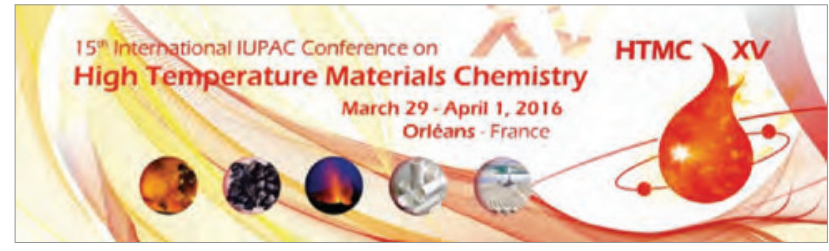

$15^{\text {th }}$ International IUPAC Conference on High Temperature Materials Chemistry (HTMC-XV)

A HTMC-XV terá lugar de 29 de Março a 01 de abril de 2016, em Orleães e será a 15. a reunião de uma série de conferências que são realizadas a cada três anos, tendo a última ocorrido em Beijing, China, em 2012.

Esta conferência pretende reunir participantes de áreas tão diversas como Química, Ciência dos materiais, Metalurgia e Ciências da terra e planetária, que trabalham em fenómenos de alta temperatura em materiais sólidos e líquidos.

Os Tópicos da conferência são: Materiais fundidos, cerâmicas, vidros e materiais amorfos; Corrosão, estrutura de fase e processos metalúrgicos; Materiais terrestres e planetários a alta pressão e temperatura; Materiais para aplicações em energia nuclear; Materiais para energia solar: armazenamento e receptores; Materiais para aplicações aeroespaciais; Transporte, condução iónica e electrónica, densificação, interfaces e superfícies; Medições termodinâmicas a altas temperaturas; Interacção entre teoria e modelação com experiência em materiais de alta temperatura;
Novos conhecimentos em ciência de materiais a temperaturas muito elevadas.

htmc15@cnrs-orleans.fr http://htmc15.sciencesconf.org/

\section{SOLID URBAN WASTE MANAGEMENT}

XXI IUPAC CHEMRAWN CONFERENCE
April 6 $6|7| 8,2016$
CNR Plazzale Aldo Moro 7.00195 Rome (lialy)

\section{Solid Urban Waste Management - XXI IUPAC CHEMRAWN Conference}

O objectivo da XXI IUPAC CHEMRAWN Conference é apresentar uma perspectiva abrangente sobre os actuais desafios da Gestão de Resíduos Sólidos Urbanos e novos rumos para a sua exploração, especialmente através de uma abordagem "de resíduo a recurso". A conferência reunirá especialistas do "mundo urbanizado", bem como peritos de países em desenvolvimento, dando uma oportunidade quer a cientistas de várias áreas quer a organizações, decisores políticos e grupos envolvidos no controlo e certificação, para discutir tendências futuras e acções necessárias. Esta conferência será precedida de um Curso de Formação Avançada focado em estratégias emergentes de biotecnologia que visam valorizar os resíduos.

De entre os temas abordados destacam-se: Energia a partir de resíduos sólidos urbanos; Recuperação, transformação e reciclagem de materiais; De resíduos orgânicos a recursos; Educação para a gestão sustentável de resíduos.

info@iupac-rome2016.it

www.iupac-rome2016

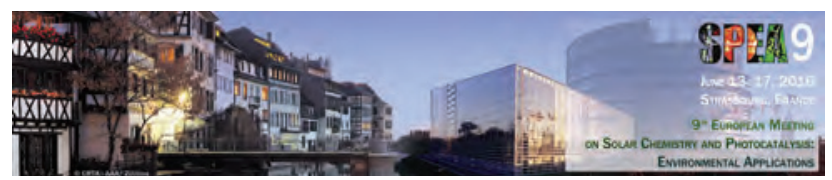

$9^{\text {th }}$ European Meeting on Solar Chemistry and Photocatalysis: Environmental Applications (SPEA9)

A SPEA é uma série de reuniões Europeias que nos últimos 15 anos ganhou notoriedade entre as reuniões mais importantes em química solar e fotocatálise. A última reunião aconteceu em Salónica (2014). A próxima reunião será em Estrasburgo em 2016 (SPEA9) e decorrerá de 13 a 17 de Junho.

Para enfrentar os desafios actuais abordando as principais preocupações societais sobre o meio ambiente, química sustentável e energia, o SPEA9 vai oferecer uma plataforma de discussão e de convívio para investigadores jovens e seniores e particularmente estudantes de doutoramento, bem como para as empresas envolvidas em Química solar e Fotocatálise.

Do programa constam lições plenárias e lições keynote, além de apresentações orais e em poster. Durante os quatro dias do encontro SPEA9 espera-se a difusão dos progressos da investigação mais avançada em fotocatálise e fotoquímica ambiental. O SPEA9 cobrirá áreas de investigação 
tão variadas como: Tratamento / desinfecção da água e do ar; Novos materiais e processos de Fotocatálise solar; Fotoquímica ambiental; Produção de hidrogénio e utilização de dióxido de carbono; Superfícies funcionalizadas; Modelação e estudos sobre mecanismos; Aplicações comerciais e de normalização; Discussão sobre a natureza fundamental ou aplicada da investigação.

spea9-contact@unistra.fr http://spea9.unistra.fr/

\section{European HETEROCYCLIC} Colloquium on CHEMISTRY

\section{$27^{\text {th }}$ European Colloquium on Heterocyclic Chemistry (ECHC 2016)}

O XXVII European Colloquium on Heterocyclic Chemistry terá lugar em Amesterdão, de 3 a 6 de Julho de 2016.

O ECHC 2016 é evento que trata de todos os aspectos da química dos heterociclos contando com a presença de oradores e participantes do meio académico e da indústria. $\mathrm{O}$ objectivo do encontro é apresentar novos resultados, estimular interacções entre o meio académico e a indústria e criar a oportunidade para o estabelecimento de redes.

O programa científico incluirá 24 conferências plenárias/ convidadas para além de comunicações orais curtas seleccionadas de entre os resumos submetidos, bem como comunicações em poster.

info@LDOrganisation.com

http://www.ldorganisation.com/v2/produits.php?langue= english\&cle_menus=1238916009

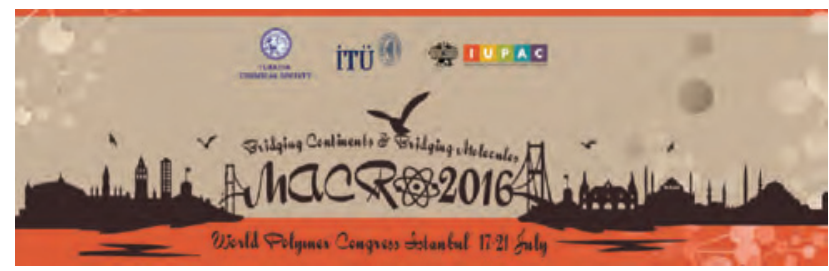

\section{$46^{\text {th }}$ IUPAC World Polymer Congress (MACR02016)}

O 46 ${ }^{\text {th }}$ IUPAC World Polymer Congress (MACRO 2016) terá lugar de 17 a 21 de Julho de 2016 em Istambul, Turquia. Trata-se da maior conferência multi-simpósio internacional dedicada a todos os aspectos da ciência e da engenharia de polímeros, sendo um encontro bienal da Divisão de Polímeros da IUPAC.
De entre os tópicos considerados pelo congresso, destacam-se: Desenvolvimentos recentes em síntese de polímeros; Caracterização de polímeros por técnicas novas e combinadas; Macromoléculas e Nanotecnologia; Macromoléculas em Biotecnologia e Medicina; Energia, óptica, e optoelectrónica; Polímeros e membranas com base em polímeros; Polímeros funcionais e inteligentes; Recursos renováveis e biopolímeros; Engenharia de polímeros, processamento e caracterização; Física de polímeros; Educação sobre polímeros; Polímeros industriais; Polímeros porosos e géis; Modelação e simulação de polímeros.

y.yagci@macro2016.org

http://www.macro2016.org/

\section{$23^{\text {rd }}$ Conference on isoprenoids \\ (4ic of Belarus, \\ September 4-7, 2016}

\section{$23^{\text {rd }}$ Conference on Isoprenoids}

A $23^{\text {rd }}$ Conference on Isoprenoids terá lugar em Minsk, República da Bielorrússia, entre 4 e 7 de Setembro de 2016. A conferência é organizada pelo Instituto de Química Bioorgânica, pela Academia Nacional de Ciências da Bielorrússia, em cooperação com a Sociedade Química Checa, sendo reconhecida pela EuCheMS. Esta série de eventos teve a sua origem 1966 por colaboração entre investigadores polacos e checos.

Esta conferência bienal junta investigadores de áreas como química, bioquímica, biologia e ecologia, interessados em diferentes aspectos dos isoprenóides e incluirá lições convidadas, comunicações orais e em painel que irão oferecer o máximo de informações no campo da química e bioquímica de isoprenóides (por exemplo, isolamento, análise, elucidação estrutural, reactividade, síntese e biossíntese), a sua actividade biológica e mecanismo de acção, vias metabólicas, aplicações, etc.

Os investigadores são encorajados a apresentar trabalhos que reflictam tendências actuais no estudo de isoprenóides incluindo por exemplo, o seu envolvimento na resolução de problemas de design de fármacos, em Ecologia química, Evolução química, Bio-sinalização, Química supramolecular e Nanomateriais entre outros.

conf@isoprenoids-23.basnet.by

http://isoprenoids-23.basnet.by

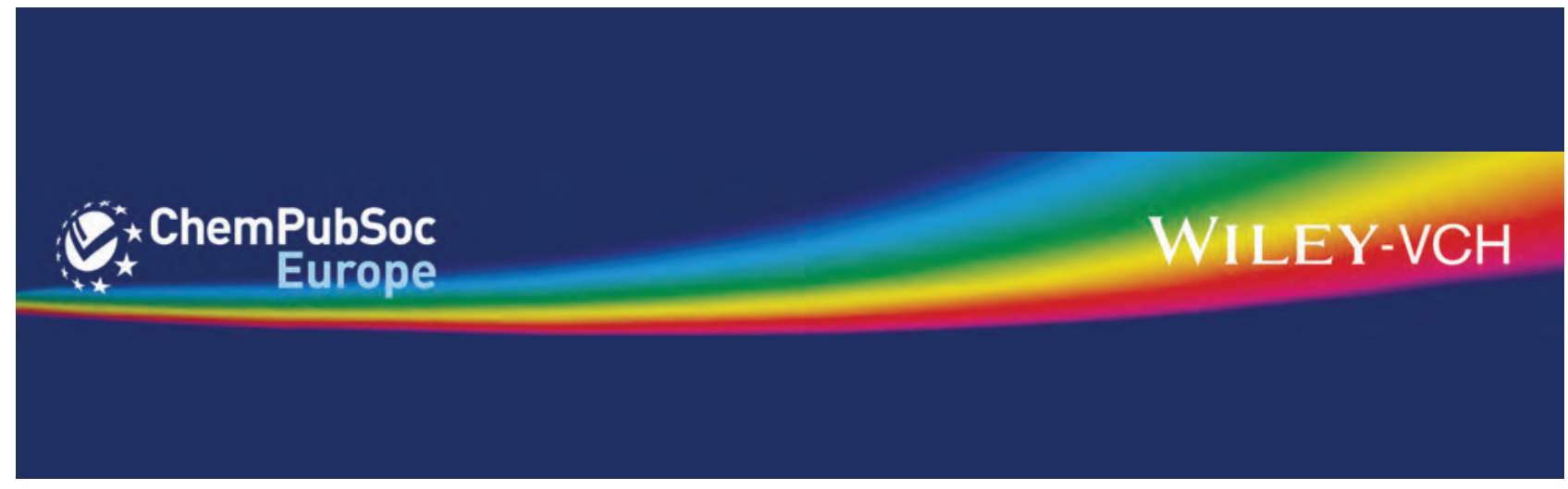

